\title{
Pratica pedagógica baseada na transversalidade: Uma proposta para a emancipação dos discentes
}

\author{
FARDIM', S. V. S.; RAGGI', D.G.; RODRIGUES ${ }^{3}$, C. F; XAVIER ${ }^{4}$, L. A.
}

1 Mestrado Profissional em Ciência, Tecnologia e Educação da Faculdade Vale do Cricaré (FVC), São Mateus, ES, Brasil.

2 Doutorado em Educação - Universidad del Norte - Revalidado pela Universidade Federal de Pernambuco - UFPE (2010). Professora e pesquisadora do programa de Mestrado Profissional em Ciência, Tecnologia e Educação, da Faculdade do Vale do Cricaré - São Mateus - ES.

3 Programa de Pós-Graduação em Educação em Ciências e Matemática do Instituto Federal do Espírito Santo (IFES), Vitória, ES, Brasil.

4 Programa de Pós-Graduação em Ensino de Física da Universidade Federal do Espírito Santo (UFES), Vitória, ES, Brasil.

*e-mail: simonevsantanna@gmail.com

\section{Resumo}

O presente resumo tem por objetivo problematizar uma prática pedagógica como proposta para a emancipação dos discentes. Baseada na transversalidade e, tendo em vista a necessidade de contemplar a realidade dos alunos, buscamos, com a prática, potencializar as aulas e o processo formativo de ensino aprendizagem. Em uma perspectiva de pedagogia libertadora, que tem como precursor o professor Paulo Freire, a metodologia utilizada foi a teórico-metodológica, em uma escola do interior do município de Marataízes, com alunos do ensino fundamental I, da educação básica. Com a proposta da sequência didática e com o olhar voltado para a dialogicidade, as aulas se pautaram em constantes pesquisas de campo feitas pelos alunos, e tiveram como base o tema meio ambiente. O percurso das atividades se deu por 10 aulas e culminou em uma visita a uma área produtiva de abacaxi, fruto esse de extrema importância para a atividade econômica do município de Marataízes - ES. Como resultado observou-se grande envolvimento e dedicação dos alunos ao desempenharem as atividades. Ficou evidente, na postura dos discentes, que o aprendizado foi para além dos muros escolares, favorecendo 0 protagonismo e a emancipação frente às situações experimentadas por meio da prática.

Palavras Chave: Emancipação, Transversalidade, Sequência Didática, Prática Pedagógica, Meio ambiente.

\section{Abstract}

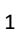


The present summary aims to problematize a pedagogical practice as a proposal for the emancipation of students. Based on transversality and, in view of the need to contemplate the students' reality, we seek, with practice, to enhance the lessons and the formative process of teaching and learning. In a perspective of liberating pedagogy, which has Professor Paulo Freire as a precursor, the methodology used was theoretical and methodological, in a school in the interior of the municipality of Marataízes, with students from elementary school I, from basic education. With the proposal of the didactic sequence and with a look turned to dialogicity, the classes were guided by constant field research done by the students, and were based on the environment theme. The course of the activities took place in 10 classes and culminated in a visit to a pineapple production area, a fruit of extreme importance for the economic activity of the municipality of Marataízes - ES. As a result, there was great involvement and dedication of students when performing the activities. It was evident, in the attitude of the students, that learning went beyond school walls, favoring protagonism and emancipation in the face of situations experienced through practice.

Keywords: Emancipation, Transversality, Didactic Sequence, Pedagogical Practice, Environment.

\section{Introdução}

O presente artigo foi desenvolvido em uma escola do interior do município de Marataízes tendo em vista os aspectos da vida cotidiana dos alunos. Todos os alunos da escola em questão são moradores da comunidade, e enfrentam as mesmas adversidades. No entanto, percebe-se nos discentes e familiares o desejo de emancipar-se. A grande maioria dos familiares não tiveram em seus estudos a continuidade que gostariam. Desta forma almejam que os seus consigam galgar tais degraus.

Com o pensamento voltado em uma pedagogia baseada em um tema gerador, a qual tem como percursor Paulo Freire, adentramos no universo da problematização de prática pedagógica que alcançasse os anseios vividos pela discentes em questão.

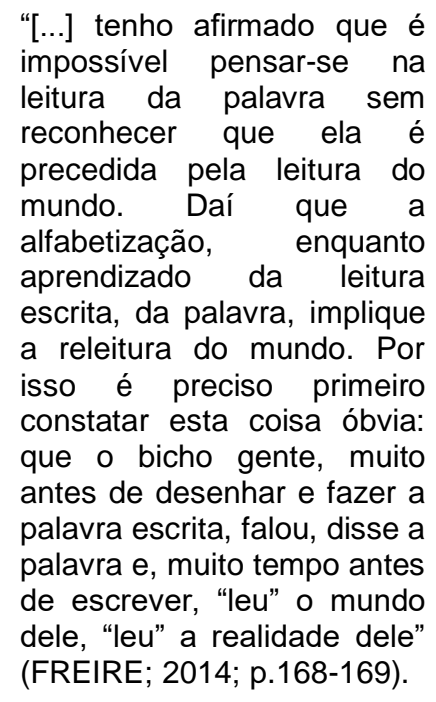

Partindo desta lógica (Silva, 2007, p. 167.) destaca a importância do tema gerador, sinalizando o encontro de sentidos para o aprendizado do educando numa perspectiva de mobilização ético-crítica e dialógica visando a construção curricular via abordagem temática, com vista a uma educação libertadora.

Neste sentido tais pensamentos coadunam em uma trajetória de compreender quem é o sujeito, qual a sua história, que leitura de mundo faz. Como é esse processo de compreender, de ler, de questionar o mundo em que está inserido. Mais uma vez Freire 2014, nos esclarece:

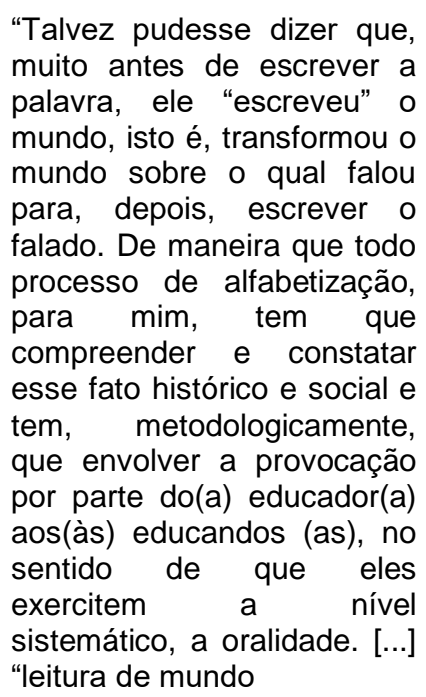

Com este olhar este trabalho teve como objetivo problematizar o favorecimento da emancipação discente por meio de práticas pedagógicas baseadas na transversalidade e na interdisciplinaridade.

\section{Metodologia}

Para conseguirmos favorecer o desnude das necessidades e temas conhecidos, questionados e de curiosidade pelos alunos tecemos discussões sobre a realidade deles. Foram indicando os caminhos que deveríamos percorrer. Dentre eles ressaltavam a preocupação com o meio ambiente em detrimento a saúde.

Ainda que seja óbvio que os aspectos biológicos constituem a base natural do meio humano, as dimensões sócioculturais e econômicas e

os

valores éticos definem, por sua vez, as orientações 
e os instrumentos com os quais o homem poderá compreender e utilizar melhor os recursos da natureza, com o objetivo de satisfazer suas necessidades (ASSIS, 1991, p.59).

Neste sentido, observamos a necessidade de contemplar em práticas baseadas na transversalidade, na interdisciplinaridade e ainda em uma pedagogia libertadora através de um percurso de dez aulas sequenciais, as quais pudessem entrelaçar a teoria e também ousasse a colocar em sala de aula a vivencia de cada indivíduo.

Com olhar voltado para a nova pedagogia que segundo Left (2009) é retratada pela Educação Ambiental, sendo esta uma pedagogia voltada ainda mais para as questões sociais, lançamos mão desta para unir-se a práxis de uma educação pautada na dialogicidade e no protagonismo discente.

Ancorado na teoria do conhecimento e aprendizagem 0 trabalho seguiu a linha de pesquisa qualitativa (Gil, 2008), envolvendo os estudos baseados na problematização de acordo com Delizoicov, 2008, e considerando a proposta da base curricular contemplando a macroárea Educação Ambiental. Trabalhando com um a sequência didática (SD) com o propósito da transversalidade e da interdisciplinaridade.

Foi oportunizado aos alunos não apenas conhecer conceitos, mas o "processo de fecundação recíproca das disciplinas envolvidas" (POMBO, 2004, p.94). Tomamos a motivação pelo conteúdo para assim trabalharmos as disciplinas da base curricular.

Por meio da SD analisamos os discursos dos discentes a) As práticas pedagógicas baseadas no trabalho interdisciplinar contribuem para 0 processo formativo dos em educação ambiental, b) 0 trabalho pedagógico baseado em uma visão sistêmica favorece a emancipação dos discentes. $O$ trabalho foi realizado com as disciplinas de língua portuguesa, geografia e ciências. Com uma carga horária de 10 aulas. Trabalhamos com instrumento de questionário, tendo em vista questões abertas, além de problematização por meio de estudo dirigido e debates.

\section{Discussão dos resultados}

Separamos algumas respostas significativas dos alunos. A maioria dos alunos analisaram que a interdisciplinaridade contribui para o processo formativo da educação ambiental.

"O estudo dos textos sobre o meio ambiente, desmatamento, as mudanças climáticas, desperta para o cuidado"
"Conhecer que para colher o fruto é preciso água, faz com que cuidemos ainda mais de nossas nascentes".

"Quando em várias
aulas estudamos o
mesmo tema, fica
mais fácil de
entender"

Alguns alunos se destacam no quesito emancipação. Para Freire (2014) a emancipação é um processo que começa a ser percebido quando o sujeito ler a palavra e reconhece a sua história. Sabe onde está e onde quer chegar. Tem conhecimento do seu lugar no mundo. Um sujeito emancipado, questiona as políticas públicas e luta pela sua classe. Não apenas sabe dos seus direitos, mas os reivindica. Para isso é preciso práticas dialógicas as quais de "voz e vez" aos discentes, que oportunize este olhar.

"A área de
preservação ambiental ajuda a manter os animais e a vegetação nativa".

"As nascentes para continuar existindo precisa vegetação".

"Vamos incentivar a reciclagem e a coleta seletiva em nossas casas, isso também colabora para com o meio ambiente"

A análise apresentada sugere que os alunos foram favorecidos no processo de emancipação através de práticas pedagógicas interdisciplinares.

\section{Conclusão}

O trabalho baseado no fato gerador proposto pelos educandos coadunando com a interdisciplinaridade e tendo em vista um tema da macroárea da base curricular que foi o meio ambiente, oportunizou o desenvolvimento de um trabalho dialógico, que contou com os três momentos pedagógicos de maneira a contemplar na problematização a busca do tema gerador, no segundo momento: os alunos através dos textos, questionários, observação do próprio meio e debates, obtiveram um crescimento em seus conhecimentos.

Finalizando na aula externa pode-se notar a mudança de olhar por parte dos educandos. No arranjo produtivo de abacaxi, se empenharam em conhecer todo o processo produtivo, como era visto o meio no olhar do produtor.

Enfim, a mudança foi exteriorizada, embora saibamos que o processo precisa ser contínuo. A 
emancipação é oportunizada a todo momento, a todo o instante e em todos os lugares.

\section{Outras recomendações}

\subsection{Figuras}

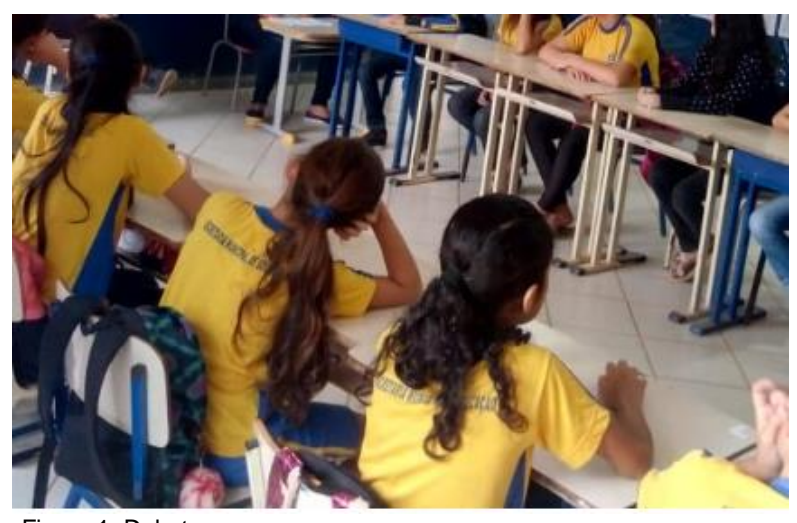

Figura 1: Debate

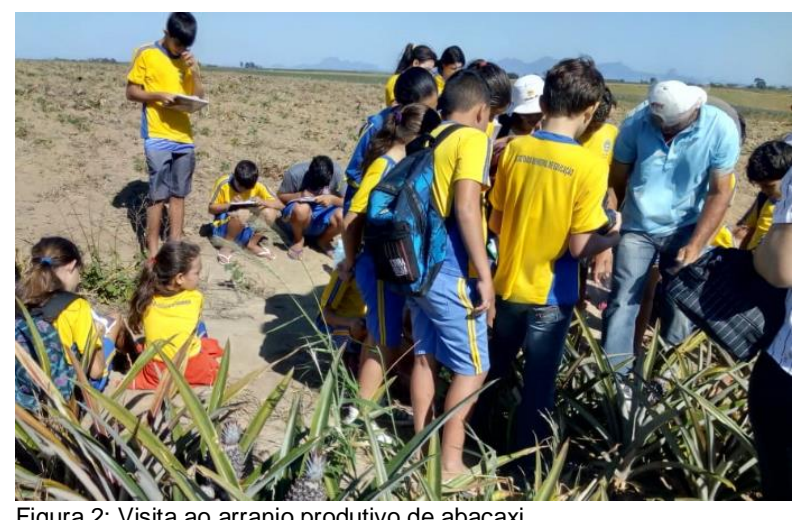

Figura 2: Visita ao arranjo produtivo de abacaxi

\section{Agradecimentos}

Os autores agradecem a CAPES pelo apoio financeiro.

\section{Referências}

\section{Livros}

[1] FREIRE, Paulo. Pedagogia dos Sonhos Possíveis. Organização, Apresentação e Notas de Ana Maria Araújo Freire. Editora Paz \& Terra.2014.

[2] Silva, Antonio Fernando Gouvêa. A busca do tema gerador na práxis da educação popular.organizadora: Ana Inês Souza. - Curitiba : Editora Gráfica Popular, 2007.

\section{Artigo de periódico eletrônico}

[3] ASSIS, E. S. A UNESCO e a educação ambiental. Em Aberto, Brasília, ano X, n. 49, p. 59-62, jan./mar, 1991

[4] LEFF, E. Complexidade, Racionalidade Ambiental e Diálogo de Saberes. Educação \& Realidade, 34, 2009. (Septiembre-Diciembre) Disponível em https://seer.ufrgs.br/educacaoerealidade/article/view/95 15. Acesso em 10.agos.2020.

\section{Livros}

[5] Gil, Antonio Carlos. Métodos e técnicas de pesquisa social. 6. ed. - São Paulo: Atlas, 2008.

[6] Delizoicov, Demétrio. Didática Geral/ Florianópolis: UFSC/EAD/CED/CFM, 2008.

[7] POMBO, O. Interdisciplinaridade: ambições e limites. Lisboa: Relógio D’Água Editores., 2004. 